\title{
Editorial
}

\section{On the $60^{\text {th }}$ Anniversary of Breeding Science}

The current issue of Breeding Science marks the $60^{\text {th }}$ year of publication of a scientific journal that has made a great impact not only in Japanese agriculture but has also contributed to the progress of agricultural production throughout the world. In the sexagenary cycle of the Chinese calendar system, the $60^{\text {th }}$ year also means a rebirth or the return of the cycle of life to its starting point. Looking back, we can clearly imagine the transformation of Breeding Science as it was first published as the Japanese Journal of Breeding on August 30, 1951 immediately after the establishment of the Japanese Society of Breeding on April 6, 1951. The first issue of the journal consisted of 11 regular papers and 5 miscellaneous papers focusing on many different species such as rabbit, silkworm, rice, maize, soybean, melon, wild Compositae and the Japanese cedar. Although Japan was still at the reconstruction stage at that time, it is surprising how research outputs from a wide range of crops and even a tree, and various animal species could be published in the journal.

Since then many scientific papers and studies encompassing traditional breeding methods and modern genomics strategies have been published. Each of these papers chronicled not only new knowledge but also the long process that led to the publication, from planning and executing the experiments in the field and laboratories, analysis of the data, preparation and processing of the manuscript, and actual publication. These collective efforts in turn led to international recognition of Breeding Science for its contribution to the understanding and progress of modern breeding methods.

On its $60^{\text {th }}$ anniversary, Breeding Science would like to
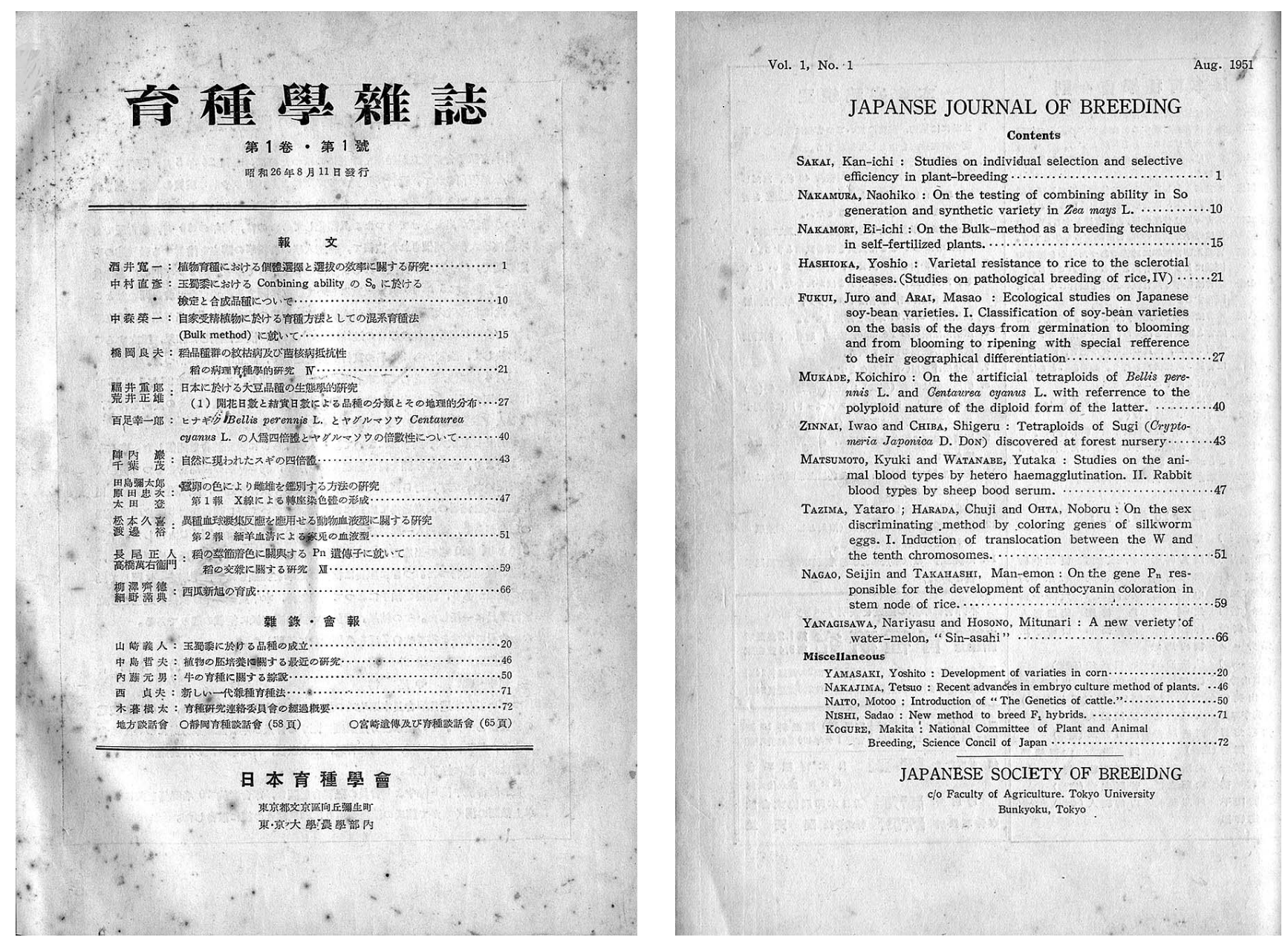

Front cover (left) and back cover (right) of the first issue of the Japanese Journal of Breeding published on August 30, 1951. All archives of Breeding Science are available at http://www.nacos.com/jsb/. 
dedicate this issue and to pay respect to all breeders and researchers who, in the last 60 years, have made significant contribution to agricultural productivity through this journal. At the same time, in the spirit of the sexagenary cycle, Breeding Science would also like to aim for a rebirth of our journal into an even better journal by increasing the impact of our publications. This is a call to renew our strong com- mitment to publish more excellent papers for innovation of breeding science.

Takuji Sasaki

Editor-in-chief

National Institute of Agrobiological Sciences 